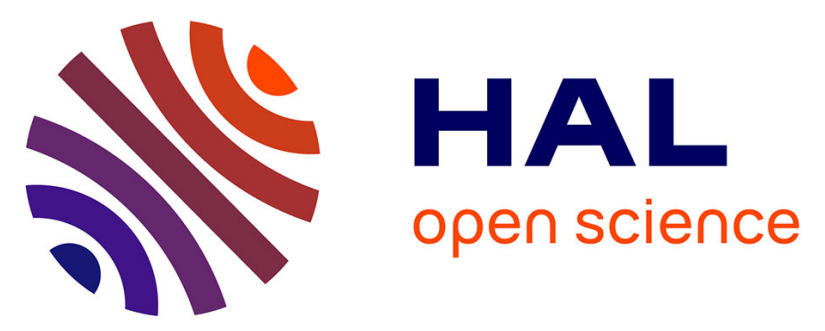

\title{
HAVING A SECOND CHILD AND ACCESS TO CHILDCARE: EVIDENCE FROM EUROPEAN COUNTRIES
}

Hippolyte d'Albis, Paula Gobbi, Angela Greulich

\section{- To cite this version:}

Hippolyte d'Albis, Paula Gobbi, Angela Greulich. HAVING A SECOND CHILD AND ACCESS TO CHILDCARE: EVIDENCE FROM EUROPEAN COUNTRIES. Journal of Demographic Economics, 2017, 83 (02), pp.177 - 210. 10.1017/dem.2017.2 . hal-01726578

\section{HAL Id: hal-01726578 \\ https://hal.science/hal-01726578}

Submitted on 6 Sep 2021

HAL is a multi-disciplinary open access archive for the deposit and dissemination of scientific research documents, whether they are published or not. The documents may come from teaching and research institutions in France or abroad, or from public or private research centers.
L'archive ouverte pluridisciplinaire HAL, est destinée au dépôt et à la diffusion de documents scientifiques de niveau recherche, publiés ou non, émanant des établissements d'enseignement et de recherche français ou étrangers, des laboratoires publics ou privés. 
Hippolyte d'Albis

Paris School of Economics - CNRS

Paula E. Gobbi

Université catholique de Louvain

\author{
Angela Greulich \\ Université Paris 1 Panthéon-Sorbonne and Ined
}

\begin{abstract}
This paper shows that differences in fertility across European countries mainly emerge due to fewer women having two children in low-fertility countries. It further suggests that childcare services are an important determinant for the transition to a second child to occur. The theoretical framework we propose suggests that (i) in countries where childcare coverage is low, there is a U-shaped relationship between a couple's probability of having a second child and the woman's potential wage, whereas (ii) in countries with easy access to childcare, this probability is positively related with the woman's potential wage. Data from the European Union Statistics on Income and Living Conditions (EU-SILC) confirm these implications when estimating a woman's probability of having a second child as a function of education. This implies that middle-income women are the most affected ones by the lack of access to formal and subsidized childcare.
\end{abstract}

Keywords: childcare, education, fertility, female employment

JEL Classification Numbers: J11, J13, J16, 011

\title{
1. INTRODUCTION
}

Birth rates across European countries have been falling since the 1960s. Although total fertility rates (TFR) stagnate at very low levels in some European countries, they have started to pick-up in other European countries [Myrskyla et al. (2009); Luci-Greulich and Thévenon (2014); Hazan and Zoabi (2015)]. Figure 1 illustrates

\footnotetext{
This paper has benefited greatly from comments from the editor, David de la Croix, an anonymous referee, Aurélien Dasré, Laurent Toulemon, and participants of the CREA workshop at the University of Luxembourg. This research was supported by the European Research Council (ERC Starting Grant DU 283953) and the "Chaire Transitions démographiques, Transitions économiques". The data used in this study is from the World Bank World Development Indicators, the OECD Family Data Base and the European Commission, Eurostat, European Union Statistics on Income and Living Conditions, waves 2003 to 2011. The providers have no responsibility for the results and conclusions of the authors. Address correspondence to: Angela Greulich, Centre d'Economie de la Sorbonne, Université Paris 1 Panthéon-Sorbonne and Ined, 75013, Paris; e-mail: angela.greulich@univ-paris1.fr
} 


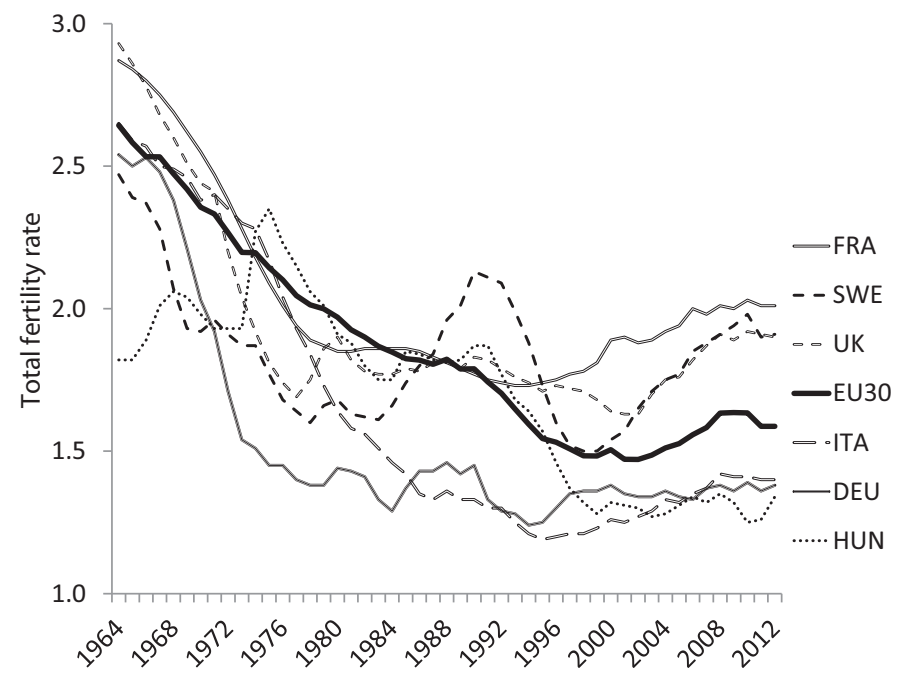

FigURE 1. Evolution of total fertility rates from 1964 to 2012 in selected European countries.

that in some countries, TFR have shown signs of an upsurge, back to replacement levels since the mid-1990s (notably in France, Sweden, Norway, Denmark, the United Kingdom, and Belgium), whereas in others, fertility has continued to drop below the European average, stagnating under 1.5 children per woman (as in Italy, the Czech Republic, Germany, Hungary, and Poland). This paper contributes to a better understanding of the factors that have made it possible for fertility rates to recover in some countries but not in others.

This reversal of fertility trends in some countries is caused in part by the end of the postponement of childbearing among younger generations [Goldstein et al. (2009); Bongaarts and Sobotka (2012)]. Fertility levels fall initially because women delay the age at which they have their first child, leading to a temporary depression of overall fertility rates. As time elapses, however, the total number of births recovers due to a catch up effect. Differences in the timing of births thus may contribute to differences in fertility rates among European countries.

However, recent research suggests that fertility differentials across European countries cannot be fully explained by differences in birth postponement only. Structural and cultural changes that come with economic development are also likely to affect fertility decisions, not only in terms of timing, but also in terms of quantum [Billari and Kohler (2004); Frejka (2008); Goldstein et al. (2009); Lesthaeghe (2010)]. Luci-Greulich and Thévenon (2013), for example, show that the rise in fertility rates back to replacement levels occurs only in those highly developed countries where female employment comes hand in hand with economic development, highlighting the importance of structural improvements that allow more and more parents, and particularly mothers, to combine work and family life. 
Although it has been argued that a below-replacement level fertility may reflect a general preference for low fertility among women and couples, most recent survey data for European countries suggest that there exist in fact barriers hindering parents from realizing their desired fertility levels, and these barriers seem more important in low-fertility countries. The surveys actually indicate stable preferences around a two-child family model for both women and men in all European countries, independent of national fertility level. Sobotka (2013) shows that the variation between countries in desired family size is generally low, centering around the two-child ideal in all European countries. Sobotka and Beaujouan (2014) show that the variance across cohorts of adults' responses to the question of "ideal family size" within European countries gets smaller over generations. Even low-fertility countries (as measured by completed fertility rates of women aged 45+) such as Poland, the Czech Republic, Slovakia, Bulgaria, Spain, Portugal, Germany, and Italy affirm an average desired fertility of two children [(Eurobarometer 2006; 2011)]. The important and persisting gap that exists between intended and realized completed fertility in countries with fertility levels below replacement level suggests that there are institutional barriers that push couples towards a lower fertility regime.

This paper sheds light on these barriers. In Section 2, we first develop a theoretical framework in order to present the mechanism under which childcare availability positively affects fertility. This relationship is empirically documented. The theory assumes a unitary household decision problem in which couples choose their fertility levels, their labor supply, and the type of childcare they desire. Men and women can supply childcare out of their own labor time or purchase childcare services from the market at a given price. The mechanism put forward with this setup is that an easier access to childcare allows parents to purchase these services instead of providing them themselves. The generated income that can be maintained after child birth facilitates the couple's decision in favor of family enlargement.

In Section 3, we first use the cross-sectional wave of the European Union Statistics on Income and Living Conditions (EU-SILC) to show that differences in fertility levels between low- and high-fertility countries mainly emerge due to fewer women having two children in low-fertility countries, suggesting a barrier for the second child birth in low-fertility countries. The theory is then extended to better understand the transition from a first to a second child. Two implications derive from the theory. The first says that the probability of having a second child in low-fertility countries, which are characterized by difficult access to childcare, follows a U-shaped relationship with women's potential wage. The decreasing part of the $\mathrm{U}$ is driven by the behavior of couples who cannot afford to purchase childcare activities in the private market. For these couples, it is often the woman who performs childcare activities for the first child and the general trend of increasing female average wages naturally increases the opportunity cost of this personal childcare, and therefore decreases the probability of having a second child. This (substitution) effect, however, subsides after a certain level of income. Once couples are able to outsource childcare, a higher female wage level allows 
the couple to buy more time from the market and encourages having a second child (increasing part of the U-shaped relationship). The second prediction is that in high-fertility countries, where childcare availability is generalized, only the positive relationship between female wage and fertility is observed. This stems from an income effect that can be seen in high-fertility developed countries, where childcare services are more accessible, leading to a probability of having a second child that is increasing with women's wage.

These theoretical implications are empirically corroborated in Section 3.3 for European countries. We estimate how the impact of women's education (used as a proxy for potential wage) on the couple's probability of having a second child differs with the access to formal childcare. We therefore use the longitudinal module of the European Union Statistics on Income and Living Conditions (waves 2003-2011) in combination with the OECD Family Database. We find that in countries where childcare coverage is low, there is a U-shaped pattern between women's education level and her probability of having a second child, whereas this relationship is continuously positive in countries with easier access to childcare. We control hereby for various side effects such as partner characteristics.

Our findings are in line with recent studies that have looked at the link between measures of female employment, education, and fertility interacting with childcare. This paper relates mostly to Hazan and Zoabi (2015), who find that higher wage inequalities in the United States lead highly educated women to outsource childcare more, driving a U-shaped relationship between women's education and fertility. ${ }^{1}$ We differ from them by looking at European countries and focusing on second child birth, as missing children of birth order two contribute most to the fertility gap between low- and high-fertility countries. The large country coverage allows applying multilevel models, which take into account the institutional context in terms of access to childcare.

Relating the cost of childcare to female labor force participation, Blau and Robins (1988) show that the price for outsourcing childcare services in the United States is negatively correlated to women's decision to both enter the labor market and to purchase childcare services. Attanasio et al. (2008) suggest that a decrease in childcare costs could explain the increase in the labor force participation of mothers of young children from the observed 0.47 rate for the cohort born in the 1940s to 0.68 for the cohort born in the 1950s in the United States. Schoonbroodt (2016) provides estimates for childcare costs paid by parents in the United States. She shows in particular that during traditional working hours, women spend three times more of their time in childcare than men.

A series of studies confirm the positive relationship between female labor force participation and access to childcare that has been found in the United States for other countries. In Quebec, Baker et al. (2008) show that an increase in female labor force participation followed the introduction of universal childcare. Similarly, using data on Swedish households, Gustafsson and Stafford (1992) show that public childcare led to higher female labor market participation and that a lower cost of childcare services positively affects the use of of these services if 
seats for children in these facilities are not rationed. For Germany, Bick (2016) shows that a large fraction of part-time working mothers would work full-time if they had better access to subsidized childcare and Wrohlich (2011) shows that increasing the availability of childcare has a greater effect on maternal employment than reducing the fees of these services.

Finally, some studies have looked at the relationship between childcare and fertility. In a cross-country analysis for countries, Borck (2014) shows that cultural differences with regard to perceived quality of external childcare can help explaining cross-country differences in levels of female labor force participation, childcare provision, and fertility. Baizán et al. (2015) find that in European countries, childcare coverage is positively related to individual-level completed fertility for all educational groups, while this association is strongest for highly educated women. In Western Germany, Hank and Kreyenfeld (2003) show that access to informal care arrangements increase the probability of having a first birth. Aassve et al. (2016) highlight that differences with regard to trusting someone outside the household to care for the children might also explain cross-country differences in fertility trends in developed countries.

This paper provides new elements to the literature. By using survey data covering a high number of countries, we show that socioeconomic differences in fertility behaviour are not universal in Europe but depend on the institutional context. More precisely, we first provide empirical evidence that having a second child is the key difference in fertility behaviour between low- and high-fertility countries in Europe. High-fertility countries also have a higher childcare coverage for children aged $0-2$. Second, we provide a theoretical framework that accounts for the facts and outlines the mechanisms. Two implications derive from the theory, and are robust in the data. First, in countries where childcare coverage is low, the probability to have a second child is U-shaped with respect to female education. And second, in countries where childcare coverage is high, female education increases the probability of having a second child.

\section{A GENERAL FRAMEWORK}

In this section, we develop a microeconomic model that allows us discussing the mechanisms relating female wages, access to childcare, and fertility. ${ }^{2}$ We treat fertility first as a continuous decision variable to derive the general mechanisms, and then more specifically, in Section 3.2, as a discrete variable in order to show the model's implications for the probability of having a second child.

\subsection{The Model}

The economy is populated by couples composed of a man and a woman, respectively, denoted by $i=m, f$. Each parent is endowed with one unit of time that is divided between childcare and work. A child needs $\phi>\bar{\phi}$ units of childcare, that can be supplied by either of the parents or outsourced, and a fixed time cost 
$\bar{\phi} \geq 0$ that can only be supplied by the mother. ${ }^{3}$ Parents differ in their wages, $w_{i}$. Consumption goods and children are public goods in the household. Couples, therefore, cooperatively choose consumption, $c$, the amount of childcare time supplied by each individual, $t_{i}$, the amount of childcare time that is outsourced, $t_{n}$, and the number of children to have, $n$.

The expected cost of outsourcing childcare is denoted by $p$ and writes as

$$
p=\epsilon p_{s}+(1-\epsilon) p_{m},
$$

where $\epsilon$ is the probability of having access to childcare services at a subsidized price $p_{s}$ and $(1-\epsilon)$ is the converse probability of not having access to those childcare services, which implies having to orient towards services a higher market price, $p_{m}>p_{s}$. At the aggregate level, the probability of having access to subsidized childcare corresponds to the coverage rate of subsidized formal childcare. This allows the model to account for an excess demand of childcare services due to the limited access to subsidized childcare - which is often the case for European countries, especially those with low-fertility rates [Thévenon (2015)]. The expected childcare cost will enter the budget constraint of the representative couple and we will perform comparative statics with respect to $p$. A increase in $p$ should be understood as a decrease in childcare coverage. One may check that equation (1) implies that $\partial p / \partial \epsilon<0$.

Denoting $\beta \in(0,1)$ as the parental preference for children relative to consumption, the maximization problem of a couple is the following ${ }^{4}$ :

$$
\max _{c, t_{f}, t_{m}, t_{n}, n} \ln c+\beta \ln n,
$$

subject to (1),

$$
c=\left[1-\left(t_{f}+\bar{\phi}\right) n\right] w_{f}+\left(1-t_{m} n\right) w_{m}-p t_{n} n,
$$

$$
\phi=t_{f}+t_{m}+t_{n}
$$

$$
1-\left(t_{f}+\bar{\phi}\right) n \geq 0
$$

$$
1-t_{m} n \geq 0
$$

and $t_{f} \geq 0, t_{m} \geq 0, t_{n} \geq 0$.

The Lagrangian of this problem is as follows:

$$
L=\ln c+\beta \ln n+\lambda t_{f}+\mu t_{m}+v t_{n}+\varphi\left[1-\left(t_{f}+\bar{\phi}\right) n\right]+\gamma\left[1-t_{m} n\right],
$$

where $(\lambda, \mu, v)$ are the Kuhn-Tucker multipliers associated to the nonnegativity constraints imposed on $\left(t_{f}, t_{m}, t_{n}\right)$, while $(\varphi, \gamma)$ are those imposed on conditions 


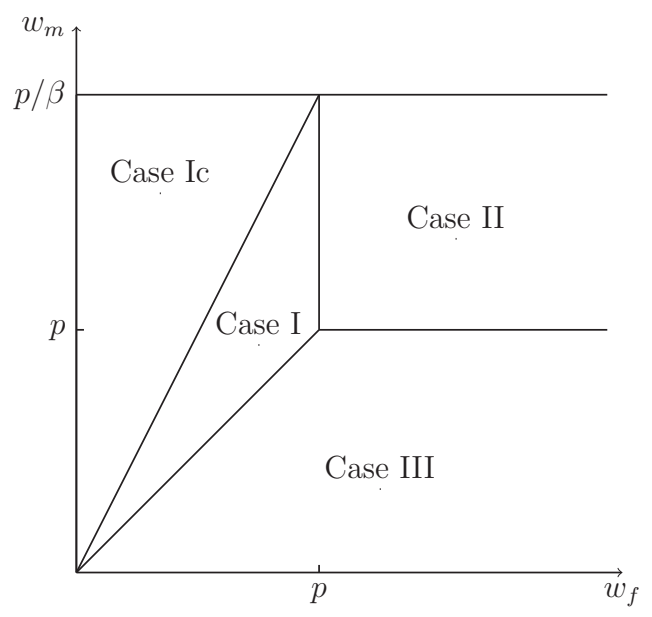

FIGURE 2. Possible cases with respect to $w_{f}, p$, and $w_{m} \in[0, p / \beta]$. Moreover, $\bar{\phi}>$ $\phi \beta /(1+\beta)$.

(5) and (6). The first-order conditions with respect to $\left(t_{f}, t_{m}, n\right)$ are as follows:

$$
-\frac{n\left(w_{f}-p\right)}{c}+\lambda-v-n \varphi=0,
$$

$$
-\frac{n\left(w_{m}-p\right)}{c}+\mu-v-n \gamma=0
$$

$$
\begin{gathered}
-\frac{\left(t_{f}+\bar{\phi}\right) w_{f}+t_{m} w_{m}+p\left(\phi-t_{f}-t_{m}\right)}{c} \\
+\frac{\beta}{n}-\varphi\left(t_{f}+\bar{\phi}\right)-\gamma t_{m}=0 .
\end{gathered}
$$

Moreover, the optimal solution satisfies

$$
\lambda t_{f}=\mu t_{m}=v t_{n}=\varphi\left[1-\left(t_{f}+\bar{\phi}\right) n\right]=\gamma\left[1-t_{m} n\right]=0,
$$
as well as equations (3) and (4).

Depending on the values of $\left(w_{m}, w_{f}, p\right)$, the optimal solution can belong to one of the three main cases described below. Figure 2 illustrates when each of these cases arise, with respect to $w_{f}, w_{m}$, and $p$.

Case I. The woman supplies all the childcare: $t_{f}=\phi$ and $t_{m}=t_{n}=0$. In this case, condition (11) implies $\lambda=\gamma=0$ and $n \leq 1 /(\phi+\bar{\phi})$. The latter inequality means that either the woman is not working and reaches the maximal fertility level given by her time constraint or she is working part-time and chooses a lower 
fertility level. Using conditions (8), (9), and (10), we obtain

$$
n=\frac{1}{(\phi+\bar{\phi})} \quad \text { if } \quad w_{f} \leq \beta w_{m} \leq p .
$$

Conversely, fertility can have an interior solution that is equal to

$$
n=\frac{\beta\left(w_{f}+w_{m}\right)}{(1+\beta)(\phi+\bar{\phi}) w_{f}} \quad \text { if } \quad \beta w_{m} \leq w_{f} \leq \min \left\{p, w_{m}\right\} .
$$

In Case I, the wage of the woman is lower than both the wage of the man and the expected cost of outsourcing childcare. The woman reaches the maximal fertility level when her wage is lower than $\beta w_{m}$, whereas she chooses a lower level of fertility when it is above. Both the constrained and unconstrained cases (denoted Case Ic and Case I, respectively) are represented in Figure 2.

When the optimal fertility is interior, we notice that an increase in the wage of the man positively affects the couple's fertility $\left(\partial n / \partial w_{m}>0\right)$, while an increase in the woman's wage affects it negatively $\left(\partial n / \partial w_{f}<0\right)$.

Case II. All the childcare is outsourced: $t_{n}=\phi$ and $t_{m}=t_{f}=0$. In this case, condition (11) implies $v=\gamma=0$ and $n \leq 1 / \bar{\phi}$. We notice that due to outsourcing possibilities, the maximal fertility level is higher than in Case I. Using conditions (8), (9), and (10), we obtain,

$$
n=\frac{1}{\bar{\phi}} \quad \text { if } \quad p \leq \frac{\beta w_{m}-w_{f}}{(1+\beta) \frac{\phi}{\phi}} .
$$

Conversely, fertility can have an interior solution that is equal to

$$
n=\frac{\beta\left(w_{f}+w_{m}\right)}{(1+\beta)\left(\bar{\phi} w_{f}+\phi p\right)} \quad \text { if } \quad \frac{\beta w_{m}-w_{f}}{(1+\beta) \frac{\phi}{\phi}} \leq p \leq \min \left\{w_{f}, w_{m}\right\} .
$$

A couple will outsource childcare when the expected cost of buying the service is not too high (below the wage of each spouse). If the cost is low, the maximal fertility level is then reached and when it increases, the fertility is more likely to be interior. In Figure 2, where it is assumed that $w_{m} \leq p / \beta$, only the unconstrained case is represented.

When the optimal fertility is interior, we notice that the wage of the man still has an income effect on fertility, $\partial n / \partial w_{m}>0$. However, an increase in the wage of the woman has both income and substitution effects, due to the childbearing time, $\bar{\phi}$. We obtain

$$
\frac{\partial n}{\partial w_{f}} \geq 0 \Leftrightarrow \phi p-\bar{\phi} w_{m} \geq 0 .
$$

If $\bar{\phi}$ is relatively low compared to the time that is outsourced, then the income effect dominates the substitution effect and, then, $\partial n / \partial w_{f}>0$. Note that a marginal increase in the male's wage increases fertility more than a marginal increase in 
the female's wage, $\partial n / \partial w_{m}>\partial n / \partial w_{f}$. This is due to the fixed cost in terms of childcare $\bar{\phi}$ supported by the woman.

Case III. The man supplies all the childcare: $t_{m}=\phi$ and $t_{n}=t_{f}=0$. In this case, conditions (11) and $\phi>\bar{\phi}$ imply $\mu=\varphi=0$ and $n \leq 1 / \phi$. Conditions (8), (9), and (10) can be used to obtain

$$
n=\frac{1}{\phi} \quad \text { if } \quad w_{m} \leq\left[\beta-(1+\beta) \frac{\bar{\phi}}{\phi}\right] w_{f} \leq p,
$$

and,

$$
\begin{aligned}
n= & \frac{\beta\left(w_{f}+w_{m}\right)}{(1+\beta)\left(\bar{\phi} w_{f}+\phi w_{m}\right)} \quad \text { if } \\
& \times\left[\beta-(1+\beta) \frac{\bar{\phi}}{\phi}\right] w_{f} \leq w_{m} \leq \min \left\{w_{f}, p\right\} .
\end{aligned}
$$

Case III is exactly symmetric to Case I for $\bar{\phi}=0$. By adding the fixed cost specific to women, we see that the constrained case is less likely.

In Case III, an increase in the wages of both the woman and the man entails income and substitution effects. If the childbearing time is larger than the childrearing time, then an increase in the man's wage has a positive effect on fertility, whereas an increase in the woman's wage has a negative effect. The opposite case is seen when childbearing time is less than childrearing time.

The next subsection looks at the implications of the theory and compares them to cross-country evidence on how fertility relates to childcare coverage.

\subsection{Theoretical Predictions and Discussion}

The right-hand side of Figure 3 shows the relationship between fertility and female wage when $w_{m}=w_{m}^{\star} \in(p, p / \beta)$ (dashed line in the left-hand side). We see that fertility is first flat with respect to female wage, as the couple is in Case Ic, then fertility decreases with female wage (Case I), and once the couple is rich enough to buy childcare services, fertility increases with respect to the wage of the woman. This implies an overall U-shaped relationship between fertility and female wage.

Figure 4 illustrates the effect of increasing the childcare coverage rate $\epsilon$, which as implied by equation (1) leads to lowering the average price of childcare, $p$, on the appearance of each case (left) and on fertility (right). A lower price increases the region in which Case II appears, where all childcare is outsourced, because couples can more easily purchase childcare.

Figure 4 shows the effect of decreasing $p$ to $p$ ' on the relationship between fertility and the wage of the woman. We see initially that fertility does not change with the wage of the woman, corresponding to the constrained fertility of Case I. But a lower expected price for childcare services (i.e., a larger share of individuals who have access to the subsidized price $p_{s}$ ) has, on average, a positive effect on fertility. This is particularly true for middle-income women, for whom the 

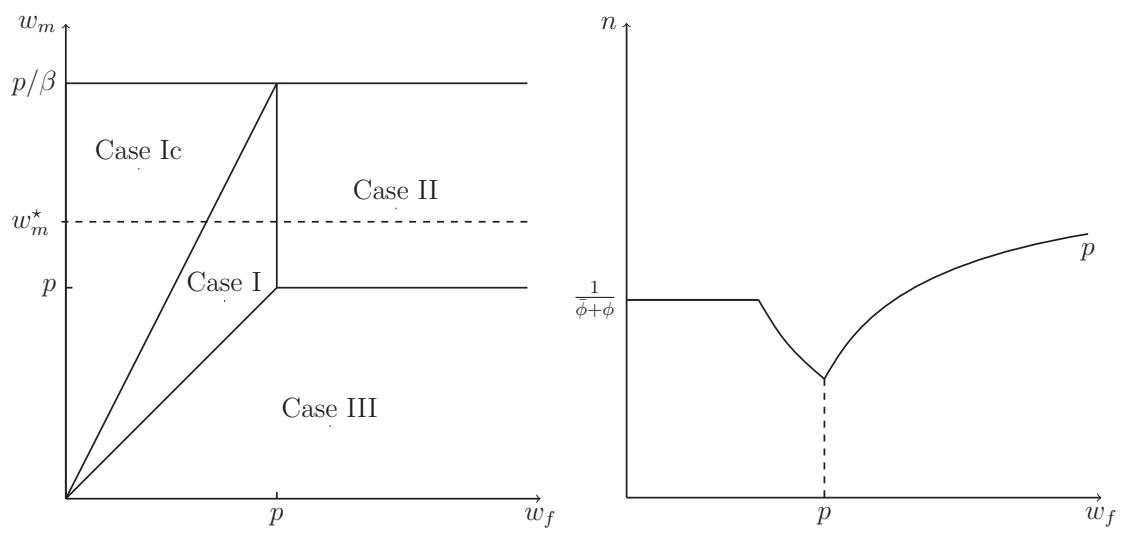

FiguRE 3. Left: Possible cases with respect to $w_{f}, p$, and $w_{m} \in[0, p / \beta]$. Moreover, $w_{m}^{\star} \in(p, p / \beta)$ and $\bar{\phi}>\phi \beta /(1+\beta)$. Right: Relationship between $n$ and $w_{f}$ for $w_{m}=w_{m}^{\star}$.
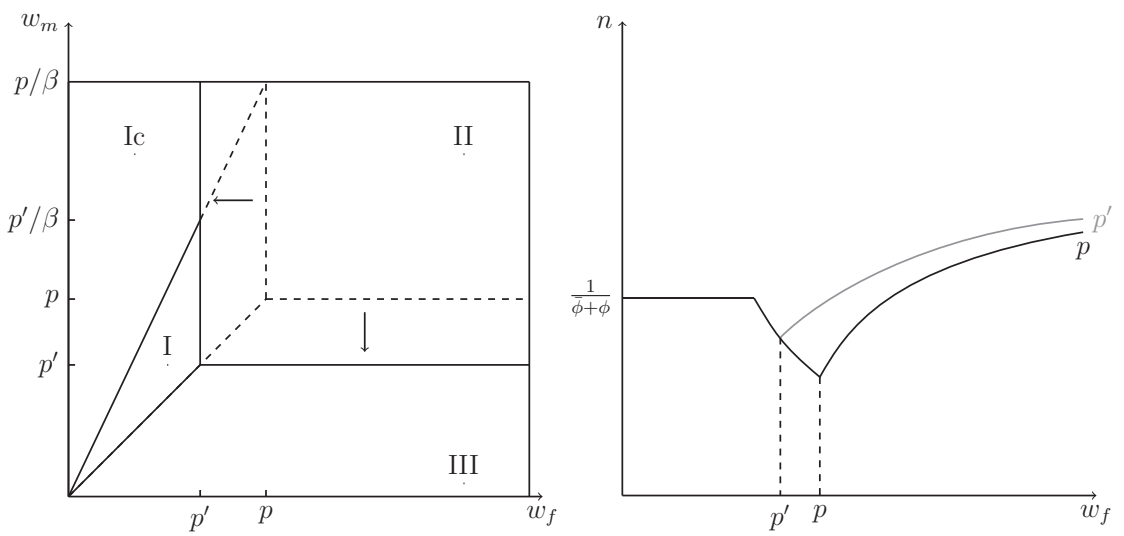

FigURE 4. Left: Possible cases with respect to $w_{f}, p$, and $w_{m} \in[0, p / \beta]$. Moreover, $\bar{\phi}>\phi \beta /(1+\beta)$. Right: Relationship between $n$ and $w_{f}$ for $w_{m} \in\left(p, p^{\prime} / \beta\right)$ and $p>p^{\prime}$.

opportunity cost to raise children is large. For high female wages, the difference in fertility when the price equals $p$ compared to when the price equals $p^{\prime}$ gets smaller as wages increase and fertility eventually converges to $\beta /(1+\beta) \bar{\phi}$. The U-shaped relationship is therefore less pronounced with a lower childcare price.

The theoretical prediction in Figure 4 is consistent with cross-country evidence using data from the Family Database (FDB). Indeed, coverage of - and therewith access to - childcare is larger in high-fertility countries. ${ }^{5}$ Several studies suggest that childcare coverage figures are a determinant rather than a consequence of TFR, ${ }^{6}$ as countries with low childcare coverage tend to have an excess demand for childcare. ${ }^{7}$ This is why we consider childcare coverage as a proxy for access 


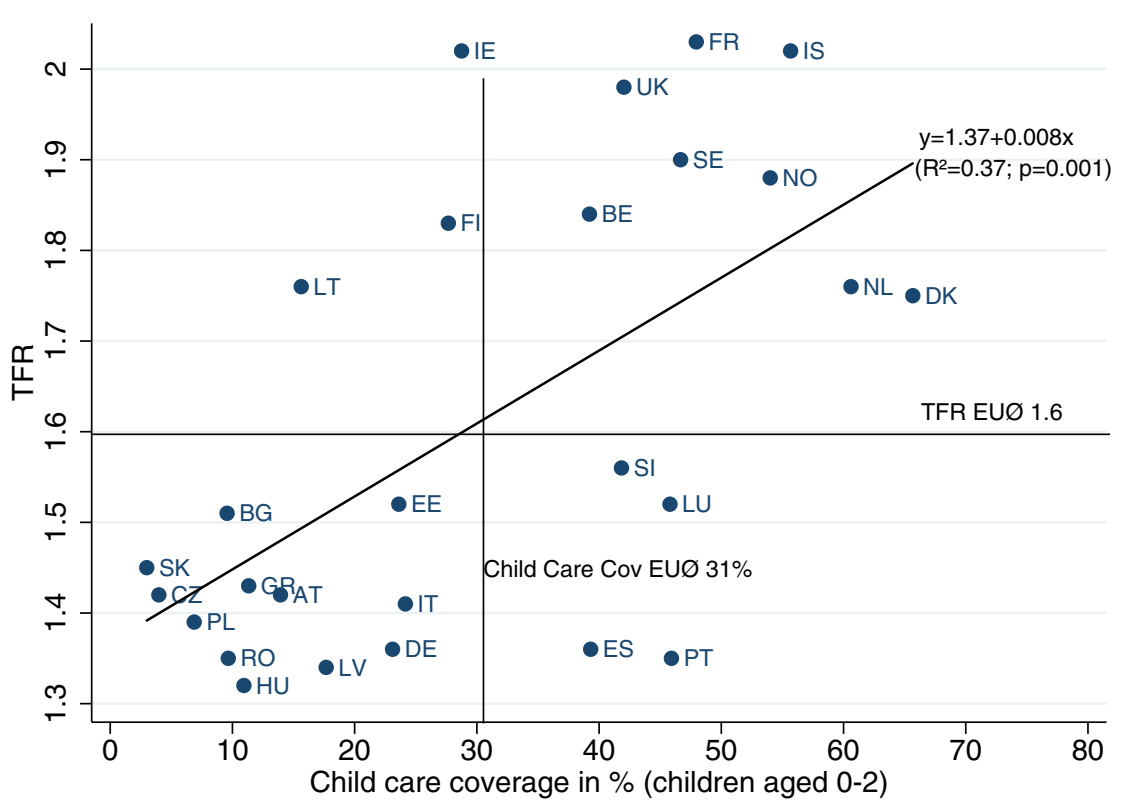

FIGURE 5. (Colour online) Total fertility rates with respect to childcare coverage (children aged $0-2)$.

to childcare for parents. The higher the coverage, the easier is generally the access for parents to childcare.

Figure 5 plots the TFR in each European country against the average enrollment rate of children under three years of age in formal childcare. We see that the correlation is significantly positive. Low-fertility countries with a TFR below the European average of 1.6 also tend to have a childcare coverage below the European average of $31 \%$, whereas high-fertility countries tend to have a coverage rate above the average.

\section{EXPLAINING DIFFERENCES IN FERTILITY ACROSS EUROPEAN COUNTRIESCheck LIST}

We first show that, among European countries, the difference in fertility rates between low- and high-fertility countries is mostly due to fewer women having a second child in low-fertility countries. Then, we extend the theoretical analysis of Section 2 to study the decision to have a second child, for women with different wages and facing different possibilities of accessing childcare. To do so, we treat fertility as a discrete variable. Finally, we provide empirical support to some implications from the theory: The probability of having a second child is U-shaped related to female education (as a proxy of women's potential wage) in countries 
where childcare coverage is low, whereas the probability of having a second child increases with female education in countries where childcare coverage is high.

\subsection{The Birth Order that Matters}

We use the 2011 cross-sectional wave of the EU-SILC to understand whether fertility differences across 26 European countries are due to differences in starting a family or to enlarging the family size. ${ }^{8}$

We base our calculations on the fertility rate for women aged 38 to 44 years old (i.e., the cohorts of 1967-1973). Women at younger ages are excluded in order to focus on completed fertility. Women at older ages are also excluded because the EU-SILC reports a decreasing number of children per woman for older ages, as these children move out of their parents' homes and can no longer be observed. Due to this partial capture of children that live in the household only, as reported in the EU-SILC, these calculated "approximate" completed fertility rates (ACFR) are somewhat downward biased. Despite this bias, this approximate measure provides a country ranking that is similar to the unbiased completed fertility measured by the Human Fertility Data Base (wave 2012, cohort 1970)..$^{9}$ The EU-SILC is thus used for our fertility analysis because it provides a large country coverage, an international comparability of socioeconomic measures, and a follow-up of individuals (used later in Section 3.3). ${ }^{10}$

The data shows a weighted average ACFR of 1.61 children per woman across the 26 European countries covered by the 2011 cross-sectional wave of EUSILC. The 12 countries with rates below this average are Germany, Spain, Italy, Switzerland, Bulgaria, Portugal, Luxembourg, Belgium, Latvia, Greece, Austria, and Estonia. The 14 countries above this average rate are the United Kingdom, the Netherlands, Lithuania, Denmark, France, Norway, the Czech Republic, Finland, Poland, Slovenia, Slovakia, Sweden, Hungary, and Iceland. The weighted average ACFR in high-fertility countries equals 1.73 , whereas it is 1.46 in low-fertility countries; the absolute fertility difference between the two groups is thus 0.27 children.

Table B.1 in Appendix B shows that in both low- and high-fertility countries, having two children is the most frequent situation for women aged 38 to 44 years old (40\% in low-fertility against $42 \%$ in high-fertility countries). Childlessness is higher in low-fertility countries, and the proportion of women having three and four children is higher in high-fertility countries. The absolute differences in the proportions give, however, no direct information about the birth order that is most responsible for fertility being low in the first group of countries. The proportion of women having three and four children might be higher in high-fertility countries, but at the same time, in both country groups, only a relatively small fraction of women is concerned. This lets us suggest that the weight of children of birth order three and four for explaining differences in fertility between the two groups is smaller than the absolute difference in the proportions lets expect. The same logic applies for childless women: The difference in the proportion of childless women 


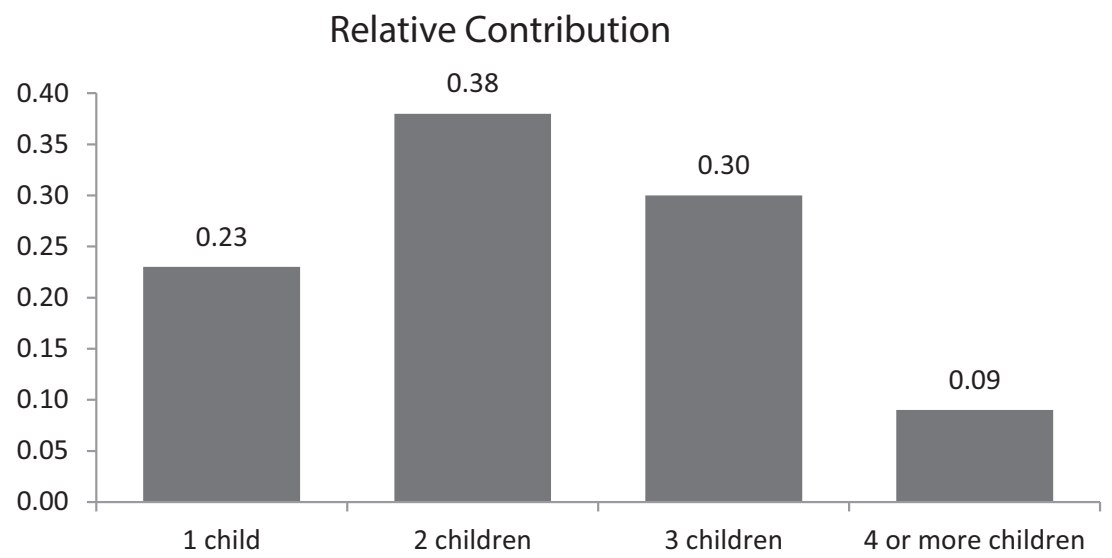

FIGURE 6. Relative contribution of fewer children of birth order $i$ to the fertility gap between high- and low-fertility countries in the EU(26).

between high- and low-fertility countries is considerable, but the proportions itself are relatively small in comparison to the proportion of women having one and two children. At the same time, the proportion of women having two children is important in the two country groups. Consequently, even if the difference between the two groups for this proportion is small, it can lead to high differences in fertility levels.

A decomposition of ACFR is thus needed to determine the contribution of each birth order to the difference in fertility levels between the two groups of countries. As detailed in Appendix 4, we first calculate for each group of countries the proportion of women having at least $i$ children (fertility rate of birth order $i$ ). The sum of these cumulative frequencies actually yields the ACFR of each country group. Then, we calculate the differences in each fertility rate of birth order $i$ between low- and high-fertility countries. These differences sum up to the absolute difference in ACFR between the two country groups.

According to these calculations, the absolute difference of 0.27 children per women between high- and low-fertility countries is composed as follows: 0.06 children are due to fewer children of birth order one in low-fertility countries, 0.10 children are due to fewer children of birth order two in low-fertility countries, 0.08 children are due to fewer children of birth order three in low-fertility countries, and 0.02 children are due to fewer children of birth order four in low-fertility countries. Therewith, the fertility gap is mainly explained by fewer children of birth order two. Figure 6 illustrates the relative contribution of each birth order to the fertility gap. Fewer children of birth order one account for $23 \%$ of the gap in ACFR between high- and low-fertility countries, fewer children of birth order two for $38 \%$, fewer children of birth order three for $30 \%$, and fewer children of birth order four for $9 \%$. 
Our calculations show that fertility differences between European countries mainly emerge due to fewer children of birth order two, suggesting that in lowfertility countries, most women have a first child, but fewer decide in favor of a second one. Following the same calculation method, Breton and Prioux (2005) find a somewhat higher contribution of children of birth order three in comparison to children of birth order two to fertility differences between European countries. This is due to the fact that they do not include Eastern European countries in their sample and focus on a generation that is 10 years older. At the same time, their study and ours consistently find that fewer children of birth order one (i.e., higher childlessness) are not the main explanation for low-fertility levels. ${ }^{11}$

Additional evidence that fertility differences between European countries mainly result from differences in second child birth can be obtained when including younger cohorts in our analysis. We therefore look at the transition probabilities of women aged 15 to 44 years old. To observe the probabilities of child birth by birth order, we use the longitudinal database of the EU-SILC (waves 2003 to 2011). The rotational panel with a follow-up of individuals for a maximum period of four years allows identifying child births that occur during the observed period.

We observe that among women aged 15-44 years who are childless in the beginning of the observed period, $5 \%$ have a first child during the observed period. Among women having one child, $10 \%$ have a second child and among women having two children, $5 \%$ have a third child during the observed period.

Figure 7 plots each country's average probability of observed birth of a child of birth order one, two, and three for women aged 15-44 years old against the country's TFR. The probability to observe a child's birth is higher in high-fertility countries for all birth orders. Figure 7 reveals a separation of European countries in two clearly distinguishable fertility regimes, low versus high ones, with low versus high probabilities of a child's birth. The difference between the two regimes is most striking for a second child birth (middle panel of Figure 7), which is not only due to a level effect. In low-fertility countries, the probability of a second child birth is $66 \%$ lower than in high-fertility countries, against $40 \%$ for the probability of first and third child birth. Our finding that countries with low and high TFR differ most in the transition to a second child underlines the importance of children of birth order two that was revealed by the previous ACFR analysis focusing on older cohorts only which already have completed their family size.

The following subsection depicts the mechanisms behind a couple's decision of having a second child.

\subsection{The Decision of Having a Second Child in Theory}

To focus on the transition from the first to the second child, we modify the general model as structured above by considering that $n$ is discrete rather than continuous. As the utility function is increasing and concave with respect to $n$, a couple will have two or more children if the indirect utility when $n=2$ is higher than the indirect utility when $n=1$. 

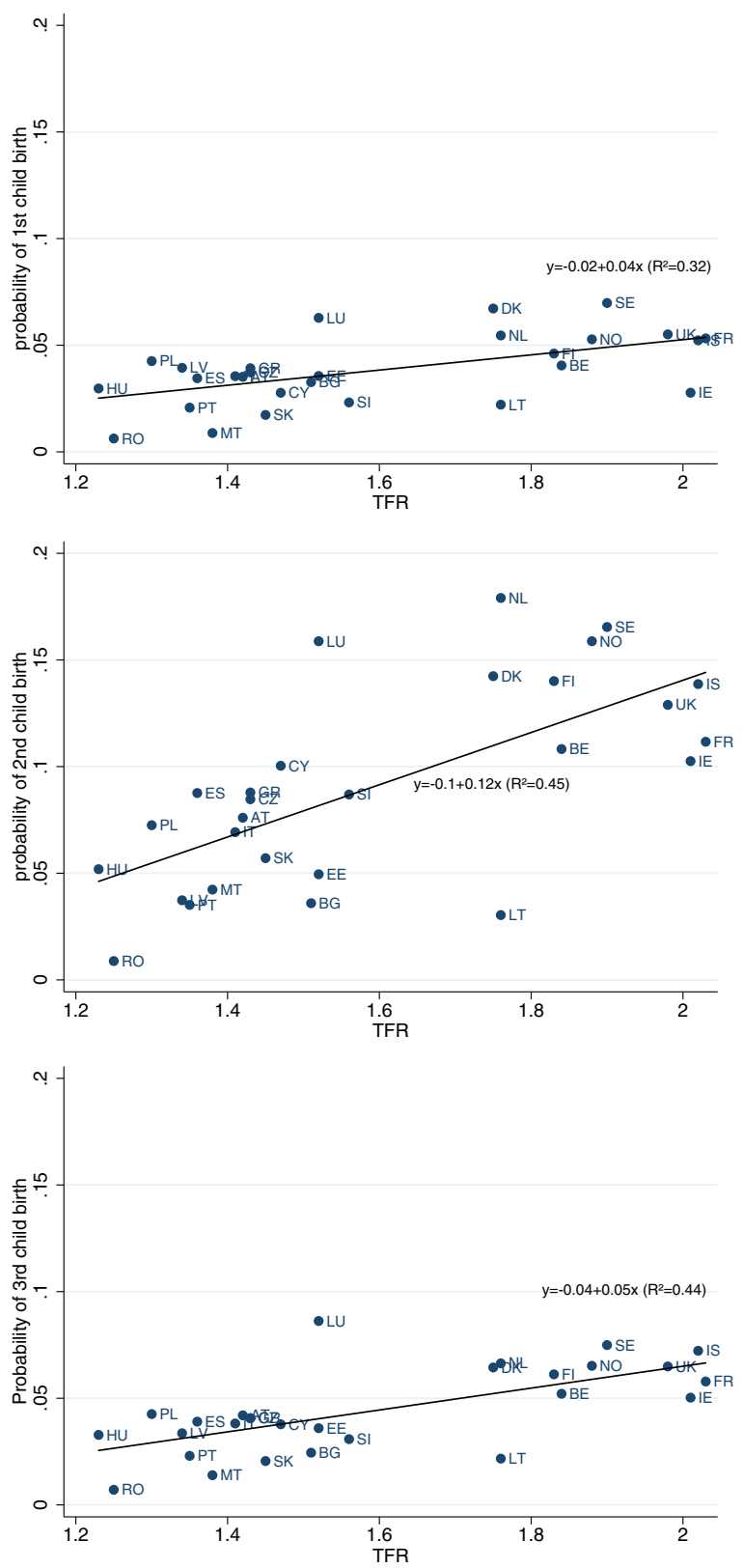

FigURE 7. (Colour online) Probability of child birth of birth order 1 (top), 2 (middle), and 3 (bottom) vs. TFR. 
Let us assume that the parameter restrictions are such that we are either in Case I, where the woman supplies all the childcare, or in Case II where all the childcare is outsourced $\left(w_{m}>p\right.$ and $\left.w_{f}>p\right)$, and that the fertility is interior $\left(w_{f}>\beta w_{m}\right)$. Let $\bar{u}_{n}^{\kappa}$ denote the indirect utility of having $n$ children and being in Case $\kappa=\mathrm{I}$ or $\kappa=$ II. For $w_{f}=p$, we can check that $\bar{u}_{n}^{\mathrm{I}}=\bar{u}_{n}^{\mathrm{II}}$.

Moreover, let us define $W^{\mathrm{I}}$ and $W^{\mathrm{II}}$ the female wage thresholds such that $\bar{u}_{1}^{\mathrm{I}}=\bar{u}_{2}^{\mathrm{I}}$ and $\bar{u}_{1}^{\mathrm{II}}=\bar{u}_{2}^{\mathrm{II}}$, respectively. We have

$$
W^{\mathrm{I}}:=\frac{w_{m}}{(\phi+\bar{\phi}) \lambda-1} \quad \text { and } \quad W^{\mathrm{II}}:=\frac{w_{m}-\lambda p \phi}{\bar{\phi} \lambda-1},
$$

where $\lambda:=\left(2^{\beta+1}-1\right) /\left(2^{\beta}-1\right)$. We saw that in the case where the woman supplies all the childcare, fertility decreases with the woman's wage. In this discrete variable setting, this relationship is given through the following inequality:

$$
\bar{u}_{2}^{\mathrm{I}} \geq \bar{u}_{1}^{\mathrm{I}} \Leftrightarrow w_{f} \leq W^{\mathrm{I}} .
$$

Moreover, provided that fixed costs are sufficiently large, and more precisely provided that

$$
(\bar{\phi}+\phi) \in\left(\frac{1}{\lambda}, \frac{1+\beta}{\beta} \frac{1}{\lambda}\right),
$$

the threshold $W^{\mathrm{I}}$ is larger than $\beta w_{m}$. This implies that $\bar{u}_{2}^{\mathrm{I}}>\bar{u}_{1}^{\mathrm{I}}$, if the woman's wage belongs to $\left(\beta w_{m}, W^{\mathrm{I}}\right)$. Since $\partial \bar{u}_{1}^{\mathrm{I}} / \partial w_{f}>\partial \bar{u}_{2}^{\mathrm{I}} / \partial w_{f}$ for all $w_{f}>0, \bar{u}_{2}^{\mathrm{I}}$ and $\bar{u}_{1}^{\mathrm{I}}$ will cross once for $w_{f}=W^{\mathrm{I}}$.

In the case where childcare is outsourced, fertility increases with the woman's wage, which could be expressed here as

$$
\bar{u}_{2}^{\mathrm{II}} \geq \bar{u}_{1}^{\mathrm{II}} \Leftrightarrow w_{f} \geq W^{\mathrm{II}} .
$$

Provided that $\bar{\phi} \lambda<1$, the condition for $W^{\mathrm{II}}>W^{\mathrm{I}}$ becomes

$$
p>\frac{w_{m}}{(\bar{\phi}+\phi) \lambda-1} .
$$

Then, the condition to obtain $\partial \bar{u}_{2}^{\mathrm{II}} / \partial w_{f}>\partial \bar{u}_{1}^{\mathrm{II}} / \partial w_{f}$ is $\phi p>w_{m} \bar{\phi}$, which (as we have seen in the previous section) implies that fertility increases with the woman's wage. This latter condition is compatible with the previous one provided that $p$ is sufficiently large.

Figure 8 shows $\bar{u}_{1}^{\mathrm{I}}, \bar{u}_{2}^{\mathrm{I}}, \bar{u}_{1}^{\mathrm{II}}$, and $\bar{u}_{2}^{\mathrm{II}}$ with respect to $w_{f}$ and for a large $p$ (left panel) and a small $p$ (right panel). The left panel of Figure 8 illustrates a situation in which the utility of having two children is larger for women with low or high wages than the utility of having only one child. Conversely, women with middle wages have one child. For $w_{f}<p$, the couple is in Case I in which the woman supports all the childrearing. For $w_{f}<W^{\mathrm{I}}, \bar{u}_{2}^{\mathrm{I}}>\bar{u}_{1}^{\mathrm{I}}$ so that the couple will have (at least) two children. When $W^{\mathrm{I}} \leq w_{f}<p, \bar{u}_{1}^{\mathrm{I}} \geq \bar{u}_{2}^{\mathrm{I}}$ and the couple will have one child. This is because for a woman with low wage, being out of the labor 

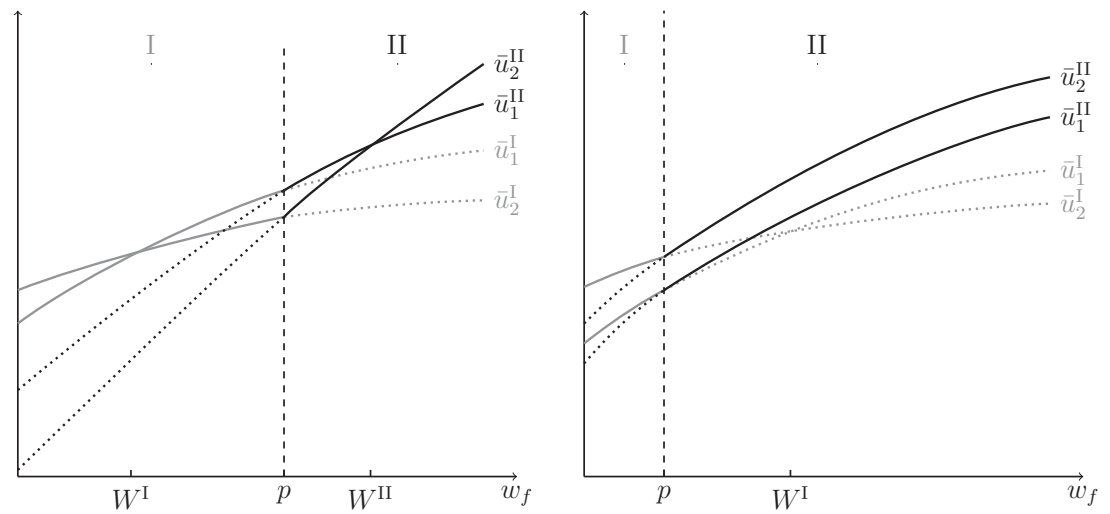

FIGURE 8. Indirect utilities of having one or two children, Case I in red and Case II in black, with a Large $p$ (left) and a Small $p$ (right).

market entails a low cost. As her wage increases, however, this cost increases and as each child costs her $\phi+\bar{\phi}$ units of time, it is optimal for the couple to have less children.

For $w_{f} \geq p$, the couple has enough income to be in Case II where it outsources childrearing. For $p \leq w_{f} \leq W^{\mathrm{II}}$, the couple has one child $\left(\bar{u}_{1}^{\mathrm{II}} \geq \bar{u}_{2}^{\mathrm{II}}\right)$ because the marginal expected cost of an extra child is larger than the utility gains. The cost of an extra child includes an increase in the opportunity cost of childbearing for the woman and a higher expected amount to pay for childrearing services. For $w_{f}>W^{\mathrm{II}}, \bar{u}_{2}^{\mathrm{II}}>\bar{u}_{1}^{\mathrm{II}}$ and the couple will have at least two children. This is due to the income effect of the increase that allows for the purchase of more childcare services in the market.

The right panel of Figure 8 shows the effect of decreasing the price of external childcare on the indirect utilities. In such configuration, $\bar{u}_{2}^{\mathrm{II}}>\bar{u}_{1}^{\mathrm{II}}$ for all $w_{f}$. A lower price for childcare implies that a lower female wage will allow the couple to reach Case II, where they can outsource childcare. Moreover, the figure also shows that couples will enter Case II before the substitution effect of the female wage becomes too large. This explains why the indirect utility of having two children always dominates the indirect utility of having one. As already present in Figure 4, Figure 8 also shows that women at the middle of the wage distribution are the most affected by changes in the expected price of childcare services.

The two panels of Figure 8 illustrate the differences in fertility patterns with respect to female wage for low- (left panel) and high- (right panel) fertility countries. The next section provides empirical evidence that the relation within European countries between the probability of having a second child and female potential wages is affected by the expected price of childcare, which will be proxied by access to/coverage of formal childcare. 


\subsection{Empirical Application}

We estimate the probability of having a second child for partnered women as a function of individual, partner, and household characteristics as well as of aggregate childcare coverage. Our main determinant of interest is the woman's education level, which serves as a proxy for her potential wage, and we analyze how the impact of education on the probability of second child birth differs with access to formal childcare. We thus do not study completed fertility, but we analyze the childbearing behaviour of women who are currently at childbearing age. This allows us applying panel data techniques that serve to reduce endogeneity between fertility and socioeconomic characteristics. We hereby focus on second child birth, as this birth order is crucial for explaining fertility differences between European countries.

Our analysis is based on 26 European countries, which, as illustrated in Figure 5, have either childcare coverage rates above or below the average of 0.31 . To model the impact of education and other individual characteristics on women's probability of second child birth, we mobilize the longitudinal data set of the EU Statistics on Income and Living Conditions, covering survey years 2003 to 2011. Figure 7 in Section 3.1 illustrates each country's average of the probability of second child birth calculated with this data base. The longitudinal database is a rotational panel with individuals followed up for a maximum period of four years (individuals are observed from wave one to four). We select women aged 15 to 45 , who already have a first child (at least one year old) in the beginning of the observed period, and their partners. The individual determinants of second child birth are observed during the year prior to the calendar year of potential second child birth. This helps reducing the risk of obtaining biased estimates due to reverse causality between the endogenous and the exogenous variables.

To allow for this time delay, individuals have to be observed for at least three consecutive waves: The third wave is needed to identify all births of birth order two that occur during the calendar year of the second wave. The first wave gives information about individual characteristics observed during the year prior to the calendar year of potential birth of a second child. Consequently, individuals who are observed for three waves have only one person-year in our compiled data base: This person-year contains information of the individual characteristics (education etc.) observed in the year prior to the calendar year of potential second child birth, as well as a dummy variable for second child birth.

For individuals who are observed for four waves, two calendar years of potential second child birth can be identified. Consequently, those who do not have a second child in the first period enter our sample with two person-years.

Individuals who are observed for only one or two waves are dropped. For these individuals, we cannot observe the individual characteristics in the year prior to the calendar year of potential second child birth. The panel contains individuals who are observed for less than four waves mainly due to the rotational design of the panel. Attrition in SILC is relatively small for individuals "at risk" of 
second child birth in comparison to first child birth, and attrition does not differ by socioeconomic characteristics, as shown by Greulich and Dasre (2017).

As the panel is short, our sample contains only either one or two person-years for each individual. This allows us applying a simple logit model, with a control for the number of person-years. We use a binary logit regression model while taking into account the characteristics of women, their partners, and the general household, as follows:

$$
P(y=1 \mid X)=\frac{\exp \left\{\beta X^{\prime}\right\}}{1+\exp \left\{\beta X^{\prime}\right\}},
$$

where $y \in\{0,1\}$ is a dummy variable for second child birth, $X$ denotes the microlevel characteristics taken into account, and $\beta$ the estimated coefficient of these variables.

Education of women and their partners are observed at the time of the survey of the year prior to the calendar year of potential second child birth. Only couples with completed education are considered (no pupils, students, trainees etc.). We construct three categories for the education level of women and their partners (by highest ISCED level attained), namely: low education for preprimary, primary, and lower secondary education, medium education for upper secondary and postsecondary nontertiary education, and high education for tertiary education. Grouping the initial six education categories into three categories allows us to obtain a sufficiently large number of observations for each category.

Besides women's and their partners' education level, we include a series of control variables in order to isolate the impact of women's potential wage on the decision of having a second child from other determinants. We include information on women's and the partners' employment status. Information on employment status (self-declared) is available on a monthly basis in SILC, which allows us to observe the employment status during a certain period before the potential conception of a second child. In order to observe the same span of time for all individuals, we restrict this period to three months. For women, we distinguish between full-time employed (employed and self-employed), part-time employed (employed and self-employed), unemployed, and inactive. Those who experience a change in employment status during the observed period figure in an extra category, but this concerns only a minority of $2 \%$. For partners, we distinguish only between full-time employed (employed and self-employed) and those who are not full-time employed, as those who are full-time employed represent the large majority of partners of women having one child (92\%). Information on employment status is missing for only $1 \%$ of partners. The control for employment status allows us not only disentangling women's wage options (as proxied by education) from their actual labour market participation, but also taking into account country heterogeneity in terms of the labour market structure (prevalence of part-time employment for women, of unemployment etc.).

In addition, we control for the woman's age, the age and sex of the first child as well as for marital status. The model fits best when integrating age as a continuous 
variable - modeling a nonlinear impact for woman's age and a linear impact for the age of the first child.

Information on individual-level access to formal childcare is not available in the longitudinal database of the SILC, which is why we have to limit our measure to cross-country variations. We use the aggregate measure of a country's childcare coverage for children aged 0 to 2 (see Figure 5: OECD Family Database, 2012) as a proxy for parents' access to childcare. Childcare coverage rates represent participation rates for 0 -to-2-year-old in formal childcare and preschool services. Data generally include children using center-based services (e.g., nurseries or day care centers and pre-schools, both public and private), organized family day care, and care services provided by (paid) professional childminders, and exclude those using unpaid informal services provided by relatives, friends, or neighbors. We use this measure in both an implicit and an explicit way in the regression models.

The implicit way consists of estimating the impact of education on the probability of second child birth by distinguishing between two groups of countries among the 26 European countries: a first group of countries with childcare coverage for children aged 0 to 2 years old that is below the European average of $31 \%$, and a second group with childcare coverage above this average (as identified in Figure 5). ${ }^{12}$

The probability of having a second child varies considerably across countries, as already suggested in Figure 7. The weighted average for the probability of second child birth in our first group of countries is 0.075 , while it amounts to 0.15 for the second group. For the first group of countries, we observe $18 \%$ of women with low education level, $60 \%$ with medium, and $22 \%$ with high education levels, whereas the distribution in the second group of countries is $20 \%, 42 \%$, and $38 \%$, respectively. As the distribution of women over education groups does not differ to a large extent in the two country groups, our estimation results are not too much sensitive to selection issues. Country-fixed effects capture, however, differences in the average returns to education between countries.

We group together all 26 countries while controlling for the country group and while interacting the country group dummy with woman's education. This avoids us dividing the sample in two subgroups. With this large sample size, we are able to analyze the effect of education on the probability of second child birth within countries of each group. To focus on these within-country variations, we introduce country-fixed effects besides the country group dummy. As some specific years may influence the probability of deciding for or against a second child, we also introduce year-fixed effects in all our regressions. The regressions are run with robust standard errors.

The explicit way for modeling access to childcare as a determinant of second child birth consists of applying a mixed-effects logistic regression. Multilevel models are useful when individuals are supposed to be nested into higher level structures [Snijders and Bosker (1999)] that may play a role in explaining events that occur at the individual level. This is of particular interest in international comparative research: We can indeed consider that individuals are nested in 
countries, each country being characterized by specific national institutions, such as childcare coverage, that may play a role on individual choices. Country effects induce correlations across observations which need to be addressed; otherwise standard errors risk to be downward biased. Multilevel models adjust for these intracountry correlations. Moreover, multilevel models can deal with unbalanced data sets [Skrondal and Rabe-Hesketh (2004)], which is important as our sample sizes vary across countries.

We integrate the country-specific contextual variable "childcare coverage" as a continuous variable in the model, and we interact childcare coverage with education. This serves to test if the effect of education differs across countries with different levels of childcare coverage, and if the effect of childcare coverage differs among education groups (cross-level effects). We apply a two-level random-intercept and random-coefficient model (by using the meqrlogit command in Stata), which fits mixed-effects models for binary responses. Country effects are specified in terms of a country error variance and fixed effects of our country-level predictor "childcare coverage." The multilevel model is thus able to analyze the impact of contextual variables on individual behavior without the assumption of homogeneity-of-regression slopes. The slope is allowed to vary randomly; random parameters have a different value for each group/country. In addition, with the interaction terms (cross-level effects), we do not only allow the intercept of the model but also the slope for the individual-level variable "education" to be random and to possibly explain it with the macrolevel variable "childcare coverage." 13

Table 1 presents the regression results of a partnered woman's probability of having a second child as a function of her education. Model 1 implicitly controls for access to childcare by including a dummy variable for countries with childcare coverage above the European average, and model 2 shows regression results of the multilevel approach.

Model 1 shows that within countries with low childcare coverage, a woman's probability of having a second child is lowest among medium-educated women. Women with high and low education levels have a significantly higher probability of having a second child in comparison to women with middle education. This result holds when controlling for partner education and woman's as well as her partner's employment status. The estimated coefficient for low education is 0.228 and for high education 0.239 in model 1 for the first group of countries with childcare coverage below the European average. Within countries with childcare coverage above the European average, a woman's probability of having a second child is significantly increasing with education. This can be seen by combining the estimated coefficients of education with the interaction terms. The estimated coefficient for low education is $-0.108(0.228-0.336)$ and $0.2638(0.229+0.0348)$ for high education in model 1 for the second group of countries. In countries with high levels of childcare coverage, low-educated women have thus the lowest probability of second child birth. The difference between middle- and high-educated women is significant, as indicated by the p-value of joint significance at the bottom of the table. In addition to the importance of women's education (figuring as potential 
TABLE 1. Estimated probability of second child birth

Model 1

Model 2

Woman's education:

Low education (primary, lower secondary)

$0.228^{*}$

Ref.

High education (tertiary)

$0.229^{* *}$

$-0.0672$

Ref.

$0.307^{* * *}$

Ref.

$-0.0704$

$-0.178+$

$-0.118+$

$0.295+$

Changing employment status

Partner's employment status:

Employed (full-time or part-time)

Not employed

No information

Control for childcare coverage:

Country group 2 (childcare coverage $\geq 0.31$ )

Country group $2 *$ low education

Country group $2 *$ high education

Childcare coverage (continuous)

Childcare coverage * low education

Childcare coverage ${ }^{*}$ high education

Demographic controls:

Woman's age

(Woman's age) $^{2}$

Age of first child:

Sex of first child is female

Couple is married

Intercept

Year-fixed effects

Country-fixed effects

Control for number of person-years

Number of observations

Proportion of second child arrival

Number of countries

Pseudo $\mathrm{R}^{2}$

Ref.

$-0.133$

$-0.0527$

$\begin{array}{ll}0.431^{*} & - \\ -0.336^{*} & - \\ 0.0348 & - \\ - & 0.026^{* * *} \\ - & -0.0114^{*} \\ - & 0.0011\end{array}$

$0.579^{* * *}$
$-0.0108^{* * * *}$
$-0.119^{* * *}$
-0.00636
$0.194^{* *}$
$-8.214^{* * *}$
Yes
Yes
Yes

22143

0.11

26

$0.583^{* * *}$

$-0.011^{* * *}$

$-0.122^{* * *}$

$-0.005$

$0.185^{* *}$

$-9.292^{* * *}$

Yes

Random

Yes
Ref.

$0.219+$

0.078

Ref.

$0.310^{* * *}$

Ref.

$-0.058$

$-0.102$

$0.293^{*}$

Ref.

$-0.051$
$-0.136$

Test of joint significance:

$\mathrm{p}$ (low educated in country group 2 )

$\mathrm{p}$ (high educated in country group 2)

0.31 
TABLE 1. Continued

Model 1

Model 2

Random effects:

Variance of the intercept

$\begin{array}{ll}- & 0.250\end{array}$

Variance of the variable "low educated"

0.007

Variance of the variable "high educated"

$\begin{array}{ll}- & 0.007 \\ - & 0.023\end{array}$

Data Source: EU-SILC LT 2003-2011 (women aged 15 to 45)

$+\mathrm{p}<0.1,{ }^{*} \mathrm{p}<0.05,{ }^{* *} \mathrm{p}<0.01,{ }^{* * *} \mathrm{p}<0.001$.

Group 1: Low childcare coverage (age 0-2) $<0.31$ : HU GR RO BG AT SK CZ PL EE IT LV IE LT FI

Group 2: High childcare coverage (age 0-2) $\geq 0.31$ : NL FR IS BE NO UK DK SE SI ES PT LU

Control for number of person-years: dummy for the second person-year for individuals with two person-years in the panel.

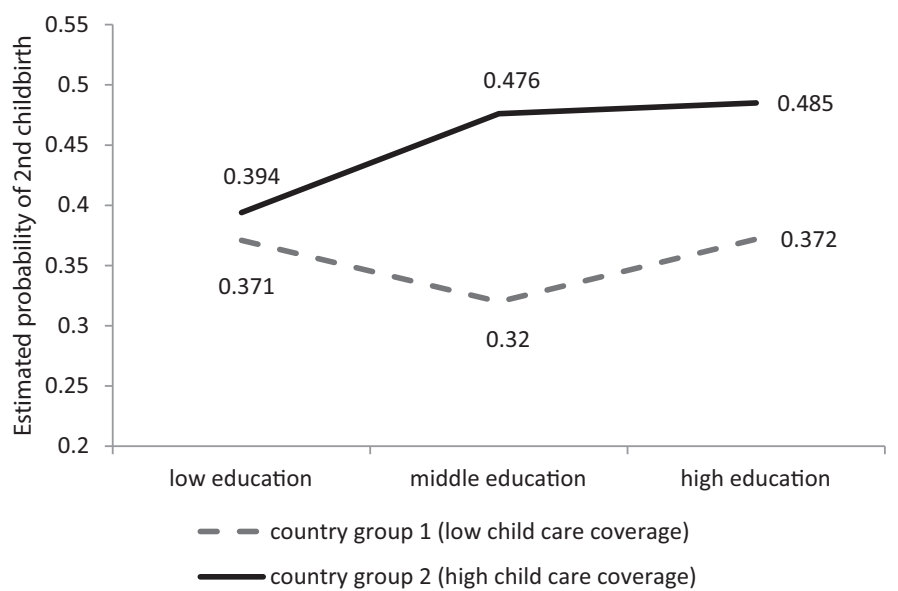

FIGURE 9. Estimated probabilities of second child birth according to woman's education, countries with difficult vs. easy access to childcare.

wage) for family enlargement, we find that - in line with our argument that it is economic resources that are important for family enlargement - unemployed and inactive women have a lower probability of second child birth in comparison to employed women. Results are similar when running a probit instead of a logit model. ${ }^{14}$

We now quantify the estimation results of model 1 by transforming the logit coefficients into estimated probabilities. ${ }^{15}$ Comparing the two country groups, Figure 9 illustrates the estimated probabilities for the reference category of women who are married to a middle-educated partner, who are 28 years old and who have a first child who is male and aged four. Within countries of the the first country group, there is a U-shaped pattern between women's education and the birth of the second child, while the relation is positive for the second group of countries. With 0.371 and 0.394 , the estimated probabilities are quite similar for low-educated women in the two country groups. At the same time, middle-educated women have a 


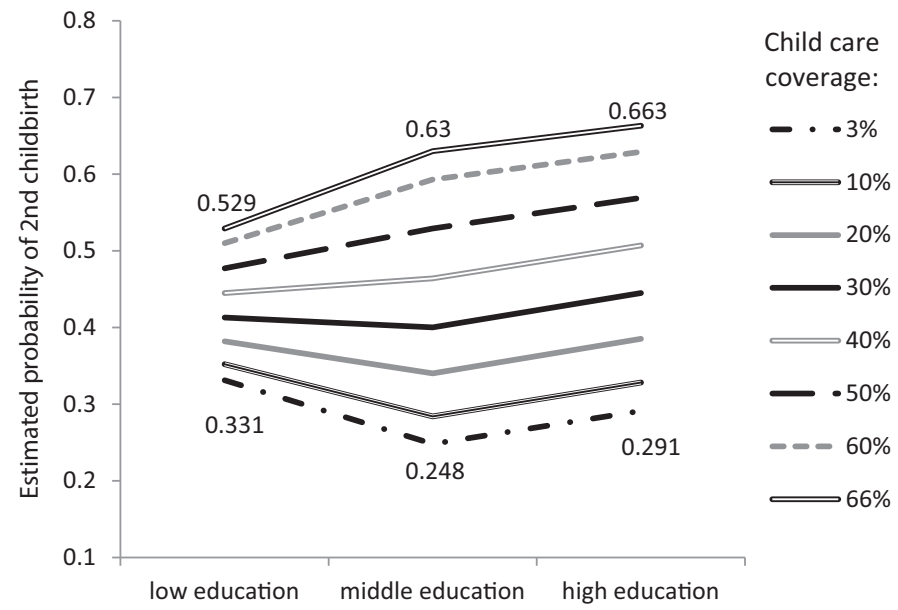

FIGURE 10. Estimated probabilities of second child birth according to woman's education, by levels of childcare coverage (children aged $0-2$ ).

lower probability of second child birth in country group $1(0.320)$ in comparison to low educated women, but a higher probability in country group $2(0.476)$. The probability is highest for high-educated women in country group 2 (0.485). In country group 1 , high-educated women have, with 0.372 , a higher probability of second child birth than middle-educated women, but this probability is low in comparison to high-educated women in countries of group two.

Results of the multilevel analysis are shown in column 2 . They show three main results. First, childcare coverage is significantly positively linked to women's probability of having a second child, independent of their educational level. Second, the interaction terms confirm that the impact of education on the probability of second child birth is influenced by the level of childcare coverage: For countries without formal childcare, women with low and high education have a higher probability of second child birth than middle-educated women. Increasing childcare coverage reduces the positive impact of low education and reinforces the positive impact of high education. Third, the interaction terms also suggest that the positive impact of childcare coverage on the probability of second child birth is lower for loweducated women and higher for high-educated women in comparison to middleeducated women. Education (at the individual level) and childcare coverage (at the macrolevel) thus both have a positive impact on the probability of having a second child and the positive impact is reinforced when these two features are combined. Results are similar when running a multilevel-probit instead of a multilevel-logit model. ${ }^{16}$

Figure 10 illustrates the estimated probabilities of the multilevel model for different levels of childcare coverage, varying between 3\% (Slovakia) and 66\% (Denmark), again for the reference category of women who are married to a 
middle-educated partner, who are 28 years old and who have a first child who is male and aged four. For low levels of childcare coverage below $31 \%$, the relation between education and the probability of second child birth is U-shaped, while the relation gets positive for higher levels of childcare coverage. In addition, Figure 10 shows that in countries with high levels of childcare coverage, the probability of second child birth is generally higher for all levels of education in comparison to those countries with lower childcare coverage.

Access to childcare facilitates thus the birth of a second child for all levels of female education. However, our results also suggest that in countries with high childcare coverage, the birth of a second child is facilitated in particular for middleand high-educated women, while in countries with low childcare coverage, it is in particular the middle-educated women who face barriers to second child birth. Given the fact that the transition to a second child is an important determinant for a country's aggregate fertility level, it seems that fertility levels are higher in countries with high childcare coverage in particular because more middle- and high-educated women pass from one to two children.

The model presented in Section 2.1 and the extended model in Section 3.2 allow us developing some intuitions for a better understanding of the patterns that are revealed by our empirical analysis. The empirical results correspond to the model's prediction of a U-shaped relationship between a couple's probability of having a second child and the woman's potential wage in countries with difficult access to childcare. The model also predicts that an easier access to childcare leads to the the fact that the probability of having a second child is increasing with woman's education. In countries with difficult access to childcare, middle-educated women face high opportunity costs and therefore tend to decide against second child birth, while high-educated women succeed in overcoming the substitution effect. An easier access to childcare reinforces the income effect, which explains that middle- and high-educated women have more facilities to enlarge the family than low-educated women.

Our results have to be interpreted with care, however, as the country-specific childcare levels can also capture other factors that might explain differences in the transition to second child birth between European countries. For example, countries might not only differ in access to childcare, but also in general wage levels for men and women. The higher the wages, the easier it may be for parents to decide in favor of an additional child. To test the robustness of our findings, we therefore run an additional specification where the country-specific wage level, gender wage inequality, and their interaction terms with education groups are also included.

To measure the wage level, we use median gross hourly wages for all employees (excluding apprentices), expressed in Euros, and in purchasing power standard (Eurostat Structure and Earnings Survey, 2010). The gender pay gap is calculated based on this measure and represents the difference between gross hourly earnings of male paid employees and of female paid employees as a percentage of gross hourly earnings of male paid employees. 
The results of this robustness check (model 3) are presented in Table C.1 of Appendix C.

Even though childcare coverage itself is no longer significant, the results confirm that for low levels of childcare coverage, low-educated women have a significantly higher probability of having a second child than middle-educated women. The significantly negative interaction term "childcare coverage $\times$ low education" shows that the higher childcare coverage, the smaller gets the coefficient of low education. Combining information of the estimated coefficients of "low education" and the interaction term "childcare coverage $\times$ low education," we find that from a childcare coverage level of $47 \%$ on, low-educated women have a lower probability of having a second child than middle-educated women.

The general wage level is found to be significantly positively related to second childbirth, whereas the impact does not significantly differ between education groups.

The results of model 3 confirm that childcare coverage shapes the educational gradient of second childbirth: In countries with high levels of childcare coverage, the educational gradient is positive, whereas in countries with low childcare coverage, the educational gradient is U-shaped. However, model 3 suggests also that general level-differences between European countries in terms of transition to second childbirth are not, or at least not only, linked to differences in childcare coverage. The general wage level seems to be an important driver for parents' decisions in terms of family enlargement. This holds for all education groups. The higher a country's wage level, the easier it seems for families to bear the financial burden of a second child.

The importance of childcare coverage, should, however, not be rejected, as results of model 3 risk being biased by multicollinearity between the wage level and childcare coverage. Richer countries tend to have both higher wage levels and higher public investments in formal childcare. One might also think of other country-specific unobserved factors that are correlated with both childcare coverage and income levels, such as gender and family norms, for example. Recent research has shown that the re-increases in TFR, that can be observed since the early 2000s, are strongest in those developed countries which have the most experienced changing gender relationships towards more gender equality, as measured, for example, by gender-equitable attitudes towards female employment, by an increasing number of out-of-wedlock births reflecting modern family norms or by increasing men's involvement in the home [Balbo et al. (2013); Neyer et al. (2013); Arpino and Esping-Andersen (2015); Goldscheider et al. (2015)].

\section{CONCLUSION}

This paper shows that fertility differences across European countries are mainly due to fewer women having two children in low-fertility countries. It suggests that in high-fertility countries, the possibility to outsource childcare has a positive 
effect on the transition from the first to the second child for a household. This transition is facilitated especially for middle- and high-educated women.

Our theoretical framework illustrates the mechanism behind this idea, robust to European survey data. In countries with low childcare coverage, the relationship between female education, as a proxy for potential wage, and having a second child is U-shaped, while in countries with high childcare coverage, the probability of second child birth is increasing with education. In countries with low childcare coverage, the probability of second child birth is thus reduced in particular for middle- and high-educated women in comparison to countries with high childcare coverage. Fertility differences between European countries thus emerge in important parts due to the fact that in countries with high childcare coverage, middleand high-educated women have a higher probability of having a second child in comparison to countries with low childcare coverage.

Our intuition behind the finding that access to childcare plays an important role in particular for middle- and high-educated women is that middle- and higheducated women have a higher opportunity cost in terms of foregone labor income when they have to provide childcare themselves. An easier access to childcare services reduces this cost and therefore increases fertility.

The U-shaped pattern implies that it is particularly the middle-educated women who decide against second child birth in countries with difficult access to childcare. A second child would urge women to stop or reduce their working activities, which makes it likely that they decide against a second child in order to maintain the family income. In these countries, high-educated women have a higher probability of second child birth than middle-educated women because the household can afford either that the woman stops or reduces her working activities or that the household purchases childcare from the private market (nannies etc.) Low-educated women have a higher probability of having a second child in comparison to middleeducated women in countries with low childcare coverage, as they have relatively low opportunity cost in terms of foregone income (indirect costs of children). In contrast, in countries with high childcare coverage where parents, and especially mothers, do not have to chose between work and childcare, the probability of second child birth increases with woman's education, as education (as proxy for income) allows to bear the direct costs of children more easily (income effect).

While childcare coverage is found to shape the educational gradient of transition to second child, our study also reveals the importance of the general wage level for explaining differences in progression probabilities between European countries. Other studies point to modern gender and family norms. Combining this information with our results, it seems thus that institutions encouraging parental employment and an egalitarian share of house and care work among partners emerge as policies that are likely to facilitate family enlargement in European countries. Childcare coverage plays here an important role, as well as access to secure employment and decent income for both partners.

This work can be extended in several directions. In particular, extending the analysis to births of other orders and improving the measures for individual access 


\section{to different types of formal and informal childcare seem to be fruitful ways of future research.}

\section{NOTES}

1 Amuedo-Dorantes and Sevilla (2014) also support a causal effect of low-skilled immigration to the United States on the reductions in the time allocated to basic childcare by college-educated mothers of nonschool age children.

2 See Himmelweit et al. (2013) for a discussion on the usefulness of formal modeling household decision making. Jones et al. (2011) also provide a clear discussion on different theoretical models that can explain the negative relationship between fertility and income.

3 In Appendix A, we show that the mechanisms made explicit in this benchmark model also hold if we introduce a good cost for children as well as a time cost.

4 The problem could have been written as an expected utility maximisation problem but this would not have changed the theoretical results.

5 Differences across childcare systems in Europe are explained in detail in Del Boca (2015).

6 See Thévenon (2015) for a literature review of the causal link between fertility levels and childcare coverage.

7 See, for example, Wrohlich (2008) for Germany, Kawabata (2014) for Japan, and the European CommissionEuropean Commission (2014) for Hungary.

8 Both of these factors can can lead to fertility differences across countries. Fertility levels significantly below replacement level can be due to difficulties in starting a family for certain women, resulting in one important group of women staying childless while another group of women have around two children (dichotomous fertility behavior). However, low fertility can also be a result of difficulties in increasing the family size rather than in starting a family, which would imply that, from a certain age on, most women are indeed mothers (i.e., childlessness is low), but few women have more than one child (homogeneous fertility behavior).

9 For the majority of countries, the classification into high- or low-fertility regimes also stays the same when using the period measure of total fertility rates (World Bank World Development Indicators, 2011). Exceptions include some Eastern European countries (Czech Republic, Slovenia, Hungary, Slovakia, Poland), which have completed fertility rates above the EU average and total fertility rates below EU average, suggesting the importance of birth postponement for younger women (tempo effect). Schmertmann et al. (2014) predict that the quantum measure of completed fertility rate will be below average for cohorts born after 1970 in these countries.

10 For a detailed discussion of measurement biases of fertility with SILC, see Greulich and Dasre (2017).

11 Furthermore, we find a somewhat higher difference between our two country groups for the transition probability from a second to a third child (women aged 38 to 44) in comparison to the one from a first to a second child, while differences in the transition to a first child are relatively small. As the transition to a third child requires having two children, and as we find that fewer children of birth order two are the main explanation for low-fertility levels, our following Section 3.2 focuses on the decision of having a second child.

12 The first group consists of Hungary, Greece, Romania, Bulgaria, Austria, Slovakia, Czech Republic, Poland, Estonia, Italy, Ireland, Lithuania, Finland, and Latvia (note that Germany is not covered by the longitudinal data base), whereas the second group consists of the Netherlands, France, Iceland, Belgium, Norway, the United Kingdom, Denmark, Slovenia, Spain, Portugal, Luxembourg, and Sweden.

13 Other macrolevel variables such as unemployment, public spending on family policies, parental leave duration and cash transfers towards families have also been integrated in the intercept equation besides childcare coverage. The effect of childcare coverage remains positive and significant, and the other macrolevel variables are less significantly correlated to second child birth than childcare coverage (results available on request). Our preferred model is thus the multilevel model with childcare coverage 
as only macrolevel variable. This avoids problems caused by multicollinearity. Moreover, having a low number of countries implies that we have limited degrees of freedom at the country level, which also speaks in favor of integrating the country-level variables one by one instead of simultaneously.

14 Probit estimation coefficients: 0.11 for low education $(90 \%$ significance level), 0.12 for high education ( $99 \%$ significance level), 0.26 for childcare coverage higher than $31 \%$ ( $99 \%$ significance level), -0.18 for the interaction of low education with high childcare coverage (95\% significance level), 0.04 for the interaction of high education with high childcare coverage.

15 Probability of second child birth: $P(Y=1 \mid X)=e^{L} /\left(1+e^{L}\right)$, where $L$ contains the estimated coefficients and $e$ is Euler's constant.

16 Multilevel-probit estimation coefficients: 0.22 for low education (95\% significance level), 0.11 for high education ( $90 \%$ significance level), 0.01 for childcare coverage $(99.9 \%$ significance level), -0.007 for the interaction of low education with childcare coverage ( $95 \%$ significance level), 0.001 for the interaction of high education with childcare coverage.

\section{References}

Aassve, Arnstein, Francesco C. Billari and Léa Pessin (2016) Trust and fertility dynamics. Social Forces 95(2), 663-692.

Amuedo-Dorantes, Catalina and Almudena Sevilla (2014) Low-skilled immigration and parenting investments of college-educated mothers in the United States: Evidence from time-use data. Journal of Human Resources 49(3), 509-539.

Arpino, B. and G. Esping-Andersen (2015) How do changes in gender role attitudes towards female employment influence fertility. A macro-level analysis. European Sociological Review 31(3), 370382.

Attanasio, Orazio, Hamish Low and Virginia Sánchez-Marcos (2008) Explaining changes in female labor supply in a life-cycle model. American Economic Review 98(4), 1517-1552.

Baizán, Pau, Bruno Arpino and Carlos Eric Delclós (2015) The effect of gender policies on fertility: The moderating role of education and normative context. European Journal of Population 32(1), $1-30$.

Baker, Michael, Jonathan Gruber and Kevin Milligan (2008) Universal child care, maternal labor supply, and family well-being. Journal of Political Economy 116(4), 709-745 (August).

Balbo, N., F. C. Billari and M. Mills (2013) Fertility in advanced societies. A review of research. European Journal of Population 29(1), 1-38.

Bick, Alexander (2016) The quantitative role of child care for female labor force participation and fertility. Journal of the European Economic Association 14(3), 639-668.

Billari, Francesco and Hans-Peter Kohler (2004) Patterns of low and lowest-low Fertility in europe. Population Studies 58(2), 161-176.

Blau, David M. and Philip K. Robins (1988) Child-care costs and family labor supply. The Review of Economics and Statistics 70(3), 374-381 (August).

Bongaarts, John and Tomáš Sobotka (2012) A demographic explanation for the recent rise in European fertility. Population and Development Review 38(1), 83-120 (March).

Borck, Rainald (2014) Adieu Rabenmutter - culture, fertility, female labour supply, the gender wage gap and childcare. Journal of Population Economics 27(3), 739-765.

Breton, D. and F. Prioux (2005) Deux ou trois enfants? Influence de la politique familiale et de quelques facteurs sociodmographiques. Population-F 60(4), 489-522.

Del Boca, Daniela (2015) Child Care Arrangements and Labor Supply. IDB working paper series no. IDB-WP-569.

Eurobarometer (2006) Eurobarometer - Childbearing Preferences and Family Issues in Europe. European Commission (Au: Maria Rita Testa, VID Austria).

Eurobarometer (2011) Family Sizes in Europe: Evidence from the 2011 Eurobarometer Survey. European Commission (Au: Maria Rita Testa, VID Austria). 
European Commission (2014) Day-Care Capacities and Demand in Hungary in 2013. Technical Report, European Employment Policy Observatory(EEPO) and Directorate DG Employment, Social Affairs and Inclusion.

Frejka, Tomas (2008) Parity distribution and completed family size in Europe: Incipient decline of the two-child family model. Demographic Research 19(4), 47-71 (July).

Goldscheider, F., E. Bernhardt and T. Lappegard (2015) The gender revolution: A framework for understanding changing family and demographic behavior. Population and Development Review 41(2), 207-239.

Goldstein, Joshua R., Tomáš Sobotka and Aiva Jasilioniene (2009) The end of lowest-low fertility? Population and Development Review 35(4), 663-700.

Greulich, Angela and Aurelien Dasre (2017) Fertility Analysis with EU-SILC: A Quantification of Measurement Bias. Centre d'Economie de la Sorbonne working paper 2017.02.

Gustafsson, Siv and Frank Stafford (1992) Child care subsidies and labor supply in sweden. The Journal of Human Resources 27(1), 204-230. Special Issue on Child Care (Winter, 1992).

Hank, Karsten and Michaela Kreyenfeld (2003) A multilevel analysis of child care and women's fertility decisions in western Germany. Journal of Marriage and the Family 65(3), 584596 (August).

Hazan, Moshe and Hozny Zoabi (2015) Do highly educated women choose smaller families? The Economic Journal 125(587), 1191-1226.

Himmelweit, Susan, Cristina Santos, Almudena Sevilla and Catherine Sofer (2013) Sharing of resources within the family and the economics of household decision making. Journal of Marriage and the Family 75(3), 625-639.

Jones, Larry E., Alice Schoonbroodt and Michèle Tertilt (2011) Chapter Fertility Theories: Can They Explain the Negative Fertility-Income Relationship? In John B. Shoven (ed.), Demography and the Economy, NBER volume, Chap. 2. University of Chicago Press.

Kawabata, Mizuki (2014) Childcare access and employment: the case of women with preschool aged children in Tokyo. Review of urban and regional development studies 26(1), 40-56.

Lesthaeghe, Ron (2010) The unfolding story of the second demographic transition. Population and Development Review 36(2), 211-251 (June).

Luci-Greulich, Angela and Olivier Thévenon (2013) The impact of family policy packages on fertility trends in developed countries. European Journal of Population 29(4), 387-416.

Luci-Greulich, Angela and Olivier Thévenon (2014) Does economic development 'cause' a re-increase in fertility? An empirical analysis for OECD countries (1960-2007). European Journal of Population 30, 187-221.

Myrskyla, Mikko, Hans-Petter Kohler and Francesco Billari (2009) Advances in development reverse fertility declines. Nature 460(6), 741-743.

Neyer, G., T. Lappegard and D. Vignoli (2013) Gender equality and fertility: Which equality matters? European Journal of Population 29, 245-272.

Schmertmann, Carl, Emilio Zagheni, Joshua R. Goldstein and Mikko Myrskyla (2014) Bayesian forecasting of cohort fertility. Journal of the American Statistical Association, Taylor \& Francis Journals 109(506), 500-513 (June).

Schoonbroodt, Alice (2016) Parental childcare during and outside of typical work hours. Review of Economics of the Household. Forthcoming.

Skrondal, Anders and Sophia Rabe-Hesketh (2004) Generalized Latent Variable Modeling: Multilevel, Longitudinal, and Structural Equation Models. FL, USA: Chapman Boca Raton and Hall/CRC.

Snijders, T. and R. Bosker (1999) Multilevel Analysis. London: Sage Publications.

Sobotka, Tomáš (2013) Pathways to Low Fertility: European Perspectives. Expert Paper No. 2013/8, United Nations Department of Economic and Social Affairs, Population Division.

Sobotka, Tomáš and Éva Beaujouan (2014) Two Is best? The persistence of a two-child family ideal in Europe. Population and Development Review 40(3), 391-419 (September).

Thévenon, Olivier (2015) Chapter Decreasing fertility in Europe: Is it a policy issue? In Christiane Timmerman, Jacques Haers, Sara Mels, Koenraad Matthijs, and Karel Neels (eds.), Population Change 
in Europe, the Middle-East and North Africa: Beyond the Demographic Divide. Ashgate, Routledge, New York, 81-118.

Wrohlich, Katharina (2008) The excess demand for subsidized child care in Germany. Applied Economics 40(10), 1217-1228.

Wrohlich, Katharina (2011) Labor Supply and Child care Choices in a Rationed Child Care Market. DIW Berlin discussion paper no. 1169.

\section{APPENDIX A: EXTENSION WITH GOODS COST FOR CHILDREN}

Here, we show that introducing a good cost for children in the budget constraint does not change the qualitative predictions of the theory.

Assuming all else equal as in Section 2.1, the budget constraint faced by couples can now be written as

$$
(2+\alpha n) c=\left(1-\left(t_{f}+\bar{\phi}\right) n\right) w_{f}+\left(1-t_{m} n\right) w_{m}-p t_{n} n
$$

where $\alpha$ represents the share of consumption that each child needs.

The three cases that were identified are then modified as shown below. In particular, we derived the optimal interior $n$ in each case.

I. The woman supplies all the childcare. If $\mu, v>0$ and $\lambda=0 ; t_{m}, t_{n}=0$,

$$
\begin{aligned}
n^{\mathrm{I}}= & \frac{\alpha(\beta-1)\left(w_{f}+w_{m}\right)-2(1+\beta)(\bar{\phi}+\phi) w_{f}}{2 \alpha \beta(\bar{\phi}+\phi) w_{f}} \\
& +\frac{\sqrt{\left((2(\bar{\phi}+\phi)+\alpha) w_{f}+\alpha w_{m}\right)\left(\alpha(\beta-1)^{2}\left(w_{f}+w_{m}\right)+2(1+\beta)^{2}(\bar{\phi}+\phi) w_{f}\right)}}{2 \alpha \beta(\bar{\phi}+\phi) w_{f}} .
\end{aligned}
$$

II. All of the childcare is outsourced. If $\lambda, \mu>0$ and $v=0 ; t_{f}, t_{m}=0, t_{n}=\phi$,

$$
\begin{aligned}
n^{\mathrm{II}}= & \frac{\alpha(\beta-1)\left(w_{f}+w_{m}\right)-2(1+\beta)\left(\bar{\phi} w_{f}+\phi w_{m}\right)}{2 \alpha \beta\left(\bar{\phi} w_{f}+\phi w_{m}\right)} \\
& +\frac{\sqrt{\left((2 \bar{\phi}+\alpha) w_{f}+(2 \phi+\alpha) w_{m}\right)\left(\alpha(\beta-1)^{2}\left(w_{f}+w_{m}\right)+2(1+\beta)^{2}\left(\bar{\phi} w_{f}+\phi w_{m}\right)\right.}}{2 \alpha \beta\left(\bar{\phi} w_{f}+\phi w_{m}\right)}
\end{aligned}
$$

III. The man supplies all the childcare. If $\lambda, v>0$ and $\mu=0 ; t_{f}, t_{n}=0, t_{m}=\phi$,

$$
\begin{aligned}
n^{\mathrm{III}}= & \frac{(\beta-1) \alpha\left(w_{f}+w_{m}\right)-2(1+\beta)\left(\bar{\phi} w_{f}+p \phi\right)}{2 \alpha \beta\left(\bar{\phi} w_{f}+p \phi\right)} \\
& +\frac{\sqrt{\left(2 \bar{\phi} w_{f}+\left(w_{f}+w_{m}\right) \alpha+2 p \phi\right)\left((\beta-1)^{2} \alpha\left(w_{f}+w_{m}\right)+2(1+\beta)^{2}\left(\bar{\phi} w_{f}+p \phi\right)\right)}}{2 \alpha \beta\left(\bar{\phi} w_{f}+p \phi\right)} .
\end{aligned}
$$

For the parameter values given above, and $\alpha=0.4$ the mechanisms suggested in Section 2.1 and the relationship between fertility and female wage shown in Figure 4 do not change when adding a cost of children in terms of goods. 
TABLE B.1. Approximate completed fertility rate (women aged 38-44), proportion of women with $i$ children and proportion of women with at least $i$ children for high- and low-fertility countries

\begin{tabular}{lccccccc}
\hline & ACFR & $p_{0}$ & $p_{1}$ & $p_{2}$ & $p_{3}$ & $p_{4}$ & $p_{5}$ \\
\hline Low-fertility countries $(l f)$ & 1.46 & 0.22 & 0.27 & 0.40 & 0.09 & 0.03 & 0.02 \\
High-fertility countries $(h f)$ & 1.73 & 0.15 & 0.23 & 0.42 & 0.15 & 0.05 & 0.02 \\
Difference $(h f-l f)$ & 0.27 & -0.06 & -0.04 & 0.02 & 0.06 & 0.02 & 0.00 \\
& & & $\mathrm{FR}_{1}$ & $\mathrm{FR}_{2}$ & $\mathrm{FR}_{3}$ & $\mathrm{FR}_{4}$ & $\mathrm{FR}_{5}$ \\
& & & 0.78 & 0.52 & 0.12 & 0.03 & 0.02 \\
Low-fertility countries $(l f)$ & & & 0.85 & 0.62 & 0.20 & 0.05 & 0.02 \\
High-fertility countries $(h f)$ & & & 0.06 & 0.10 & 0.08 & 0.02 & 0.00 \\
Difference $(h f-l f)$ & & & & & & & \\
\hline
\end{tabular}

Data Source: EU SILC CS 2011; women aged 38-44.

Low-fertility countries $(l f)$ : ACFR $<1.6$.

High-fertility countries $(h f)$ : ACFR $\geq 1.6$.

\section{APPENDIX B: DETAILS ON SECTION 3.1}

Proportion of women with at least $i \in(0, N)$ children (fertility rate of rank $i$ ), $\mathrm{FR}_{i}$ :

$$
\mathrm{FR}_{i}=\sum_{i=1}^{N} p_{i}
$$

with $N$ is five or more children and $p_{i}$ is the proportion of women with $i$ children.

Approximate completed fertility rate (women aged 38-44), $\mathrm{ACFR}_{i}$ :

$$
\operatorname{ACFR}_{i}=\sum_{i=1}^{N} \mathrm{FR}_{i}
$$

Difference in fertility rates of rank $i$ between high-fertility countries $(h f)$ and low-fertility countries $(l f)$ :

$$
\mathrm{FR}_{i}^{h f}-\mathrm{FR}_{i}^{l f} .
$$

Absolute difference in the ACFR between high-fertility countries $(h f)$ and low-fertility countries $(l f)$ :

$$
\Delta \mathrm{ACFR}=\sum_{i=1}^{N}\left(\mathrm{FR}_{i}^{h f}-\mathrm{FR}_{i}^{l f}\right) .
$$

Proportion of the difference in ACFR between high- and low-fertility countries that is explained by fewer children of rank $i$ in low fertility countries:

$$
\frac{\mathrm{FR}_{i}^{h f}-\mathrm{FR}_{i}^{l f}}{\sum_{i=1}^{N}\left(\mathrm{FR}_{i}^{h f}-\mathrm{FR}_{i}^{l f}\right)} .
$$


TABLE C.1. Estimated probability of second child birth - robustness check

Model 3

Woman's education:

Low education (primary, lower secondary)

Middle education (upper and post-secondary)

$0.612+$

High education (tertiary)

Ref.

Partner education:

Low education (primary, lower secondary)

0.125

Middle education (upper and post-secondary)

$-0.0794$

High education (tertiary)

Woman's employment status:

Employed full-time

Employed part-time

Unemployed

$-0.176+$

Inactive

$-0.109$

Changing employment status

Partner's employment status:

Employed (full-time or part-time)

Ref.

Not employed

No information

Aggregate level variables:

Childcare coverage (continuous)

0.00778

Childcare coverage * low education

$-0.0130^{*}$

Childcare coverage * high education

0.000305

Wage level (continuous)

$0.110^{* * *}$

Wage level ${ }^{*}$ low education

0.00984

Wage level * high education

0.00369

Gender wage gap (continuous)

0.0210

Gender wage gap * low education

$-0.0191$

Gender wage gap * high education

0.00521

Demographic controls:

Woman's age

$0.580^{* * *}$

(Woman's age) ${ }^{2}$

$-0.0108^{* * *}$

Age of first child

$-0.121^{* * *}$

Sex of first child is female

$-0.00477$

Couple is married

$0.184^{* *}$

Intercept

$-10.13^{* * *}$

Year-fixed effects

Yes

Country-fixed effects

Random

Control for number of person-years

Yes

Number of observations 
TABLE C.1. Continued

Model 3

Proportion of second child arrival

0.112

Number of countries

26

Random effects:

Variance of the intercept

0.114

Variance of the variable "low educated"

0.000

Variance of the variable "high educated"

0.022

$+\mathrm{p}<0.1,{ }^{*} \mathrm{p}<0.05,{ }^{* *} \mathrm{p}<0.01,{ }^{* * *} \mathrm{p}<0.001$

Control for number of person-years: dummy for the second person-year for individuals with two person-years in the panel. 